\title{
Evaluation of Existing Work System Models with Particular Consideration of Demographic Change
}

\author{
Uwe Dombrowski, Anne Reimer, and Christoph Riechel \\ Institute of Advanced Industrial Management, \\ Technische Universität Braunschweig, Braunschweig, Germany \\ $\{$ u.dombrowski, anne.reimer, c.riechel\}@tu-bs.de
}

\begin{abstract}
Ergonomics and the focus on human resources are widely accepted solutions to improve the performance of enterprises. Especially the influence of demographic change raises the relevance of such approaches. In the past years, different approaches were developed to realize those scientific solutions more efficiently. But which of those scientific approaches offers the optimal solution for enterprises in a turbulent market? To answer this question, this paper shows a state of the art review of different approaches of work systems. The main goal is to clarify the differences between the approaches and illustrate the academic void.
\end{abstract}

Keywords: Work System, ergonomics, demographic change.

\section{Introduction}

How will work systems change in the future and which influence factors have to be considered? To answer this question, it is necessary to clarify how the enterprise environment will change in the next years. On this knowledge base, the company's framework can be defined and different models of work systems are analyzed.

However, research institutes took care of this topic. In a variety of studies, different megatrends were identified. Megatrends are characterized by prominent features of global politico-economic changes. It can be defined as a pattern of changes that will profoundly impress the future of producing enterprises. [1] If the results of the studies are summarized, the following five trends can be identified. [1, 2, 3, 4]

(1) Individualization and flexibility is the first megatrend. It describes the fact that the customer needs for individualization affects the product development and growing variety of product variants. A direct result of this development is a compression of information. This increases the complexity in the whole value chain. $[1,2,3,4,5]$

The (2) globalization as a further megatrend describes the expansion of the industrialization in the threshold countries. New markets and new customers need to be identified. Especially the influence of the BRIC countries (Brazil, Russia, India and China) and the Next Eleven (Bangladesh, Egypt, Indonesia, Iran, Mexico, Nigeria, Pakistan, the Philippines, Turkey, South Korea and Vietnam) increase influence factors which need to be taken into account. This results in a higher product variety for most of the enterprises. [1, 2, 3, 4] 
Besides the globalization, the megatrend (3) technology and innovation influences the products as well as the production process and the organization. With regard to product life cycles of e.g. mobile phones that is less than one year, the influence of technological innovation on the product life cycles has already enforced. Every new product requires also new processes and with it the recognition in shorter planning cycles. $[1,2,3,4]$

The megatrend (4) climate change and resource scarcity outlines the change of the climate on earth and the impact on finite resources. Companies which make sustainable use of energy, water and other natural resources will achieve a competitive advantage, but also take a risk by not recognizing this megatrend. [1, 2, 3, 4]

The named megatrends affect a work system in the way that demands on the employee increase. Especially complexity increase, technological advances and growing flexibility in the production process are leading to a higher sphere of competence. However, the greatest impact on work systems has the fifth megatrend. [6]

The fifth megatrend describes the (5) demographic change of the society. The demographic change sets challenges to the enterprises performance and global competitiveness. [7] Especially in Europe, many companies are facing this problem. [8] For the future, other countries with high industrialization have to take the consequences of demographic change into account. On the one hand, the consequences are about manpower and the guarantee having enough working age employees on the shop floor to realize a highly efficient production process. On the other hand, the challenge is about knowledge creation and lifelong learning to secure the process of innovation and productiveness of national economies. [1, 2, 3, 4]

By summarizing all the effects caused by the megatrends, it can be stated that a high impact on enterprises is expected or already has to be taken into account. In particular, the demographic change is already a challenge for the European enterprises. [9] To face those challenges, it is necessary to continuously improve and develop the methods and tools, which support the planning and operating teams within the companies. An essential requirement for this development or improving process is the definition of a state of the art work systems which takes all upcoming challenges into account.

\section{Work Systems in Germany}

The selection of the presented work system definitions was based on an extensive national and international research. On basis of the established research results and science based evaluation, an expert team selected the following work system definitions. These definitions represent the current national state of research.

The MTM (method time measurement) association defines the work system as a socio-technical system which is described by certain variables. The variables of this descriptive model include a task (describes the purpose of the work system), the resources which are person and work medium, input and output, the procedure (spatiotemporal interaction of the resources in the input-output transformation) and the environment. Micro work systems represent single-users, the macro-work systems teams, manufacturing cells, etc. [10] 
The REFA Association characterizes a work system as an operational unit in which a person (or several) uses resources, material and information to fulfill the work under certain conditions. Work systems are the physical building units of any organization and operational processes and a core component of the process-oriented work organization. [11]

The German Institute for Standardization (DIN) defines in its DIN EN ISO 6385 standard a work system as a system which includes the interaction of one or more users with the work equipment to fulfill the function of the system within the working space and the working environment under the conditions prescribed by the work tasks. [12]

Schlick et al. characterize a work system by the elements working person(s), work assignment, work task, input, output, tools, work items and environmental influences. All those elements are interconnected and any change in the system will affect all elements.[13]

This brief introduction of work system models shall just give an overview on the various models. For the future, it is important to lay a focus on the introduced megatrends in the work system models. Therefore, it is necessary to establish a framework in which the work system models and the impact of megatrends are assessed. For this, the four introduced work system models are used and an evaluation is conducted on the requirements of the megatrends. The choice of the evaluation characteristics is described in the next section.

\section{Methodology}

As shown in the previous section, there are already models which describe work systems. In order to evaluate those models with focus on the requirements caused by megatrends, it is necessary to define characteristics of a work system. Since there is no common consent on how a framework for work systems is defined, two possible approaches are introduced. The choice was made on the basis of the influence of the introduced megatrends. Especially the consideration of the demographic change as a key influence was crucial for the choice of the approaches.

The first approach is developed by Dul et al., presenting the findings of the Future of Ergonomics Committee, which was established by the International Ergonomics Association (IEA) in 2010. [14] The aim of the paper was not to provide an operational plan for human factors/ergonomics (HFE), but to give an overview on the current status in HFE. [14] Fundamental characteristics were derived from the definition of HFE and HFE specialists by the IEA, which are the following:

"Ergonomics (and human factors) is the scientific discipline concerned with the understanding of the interactions among humans and other elements of a system, and the profession that applies theoretical principles, data and methods to design in order to optimize well-being and performance." [15]

"Practitioners of ergonomics, ergonomists, contribute to the planning, design implementation, evaluation, redesign and continuous improvement of tasks, jobs, products, technologies, processes, organisations, environments and systems in order to make them compatible with the needs, abilities and limitations of people." [15] 
The identified fundamentals are that HFE is a systems approach and that it is design driven. In addition, HFE focuses on two related outcomes, which are performance and well-being. [14] The characteristics are explained in the next paragraphs.

Seeing HFE as a systems approach, it is important to define the term 'system'. Generally, a system is defined as a set of interacting and interdependent components that form an integrated whole. As shown in the previous section, HFE systems consist of humans and their environment designed to focus on relevant aspects, e.g. cognitive or environmental factors, in order to create a holistic and human-centered work system. [16] The holistic view includes various level of the system, specifically for HFE the micro, meso and macro-level. Thus, a broader view is taken to the discipline and, consequently, bringing together the various levels and the human-centered system.

Related to the system approach and the improvement of the outcomes is the characteristic that HFE is design driven. HFE is always connected to the process design and can be applied at all stages of the process, although those stages do not necessarily appear in a certain order. However, what all stages have in common is the design planning which is brought into the process by HFE specialists.

The third characteristic is the focus on the outcomes performance and well-being. Those two outcomes are interdepending which can result in trade-offs in achieving the anticipated goals. [17] Hence, it is essential that a HFE specialist is involved in the process planning and to balance the two outcomes by finding an optimal solution.

A more detailed approach was introduced by Wilson who established a framework for key characteristics of systems HFE. [18] He identified six features which are the following: Systems focus (a), Context (b), Interactions (c), Holism (d), Emergence (e) and Embedding $(f)$. Those features are explained and described in the next paragraphs.

Systems focus $(a)$ is similar to the described systems approach of the first framework approach. The focus lies on the design of a system where humans interact with their environment. The design can either be of the interactions with or within the system or of the system itself.

Context $(b)$ is considered important to HFE, because human performance and behavior is dependent on the setting or rather environment. Nowadays, context is given in a complex social or socio-technical system. Consequently, context is part of a system and it is necessary to identify relevant elements for further analysis or development.

Interaction (c) between different elements of the system is the key characteristic of HFE. Therefore, the goal is not to design components but interactions between different system elements like a person-team-organization or person-device-person interaction. Additionally, interaction is strongly connected to system complexity which effects HFE analysis and understanding.

Holism $(d)$ is another significant characteristic to HFE since various viewpoints are combined to get an appropriate overview on the situation. Consequently, the possibility is given that human characteristics like social or physical features are analyzed and then interactions with different system elements are designed and optimized.

Emergence ( $e$ ) has to be part of the fundamentals of HFE because it describes the uncertainty of human behavior. [19] In this context, effects can occur which are not 
considered in the design process, e.g. people find solutions for disadvantageous designs or even create new exploitabilities which were not considered in advance.

Embedding $(f)$ as a key characteristic describes the integration of HFE in the overall system. Essential for ergonomics is the participatory character meaning the integration of all key stakeholder and experts of the system. Yet, the organization has to decide on how to implement ergonomics in its present organization.

Comparing the two introduced approaches, the second approach is advantageous to evaluate the existing work system models due to the range of characteristics. The disadvantage of the first approach from Dul et al. is its general character and its intention to give a current status on HFE. [14] There are only three general fundamentals identified which give a first overview on important features of work systems. However, those features are not efficient for evaluation. Therefore, the second approach from Wilson provides a further range of fundamentals and allows a more detailed evaluation of the working system models.

The four introduced work systems of the previous section and the identified characteristics of Wilson are now combined to form a framework for the evaluation. A matrix is spanned with the working systems in a row and the necessary features of Wilson in the columns. The matrix is shown in figure 2 .

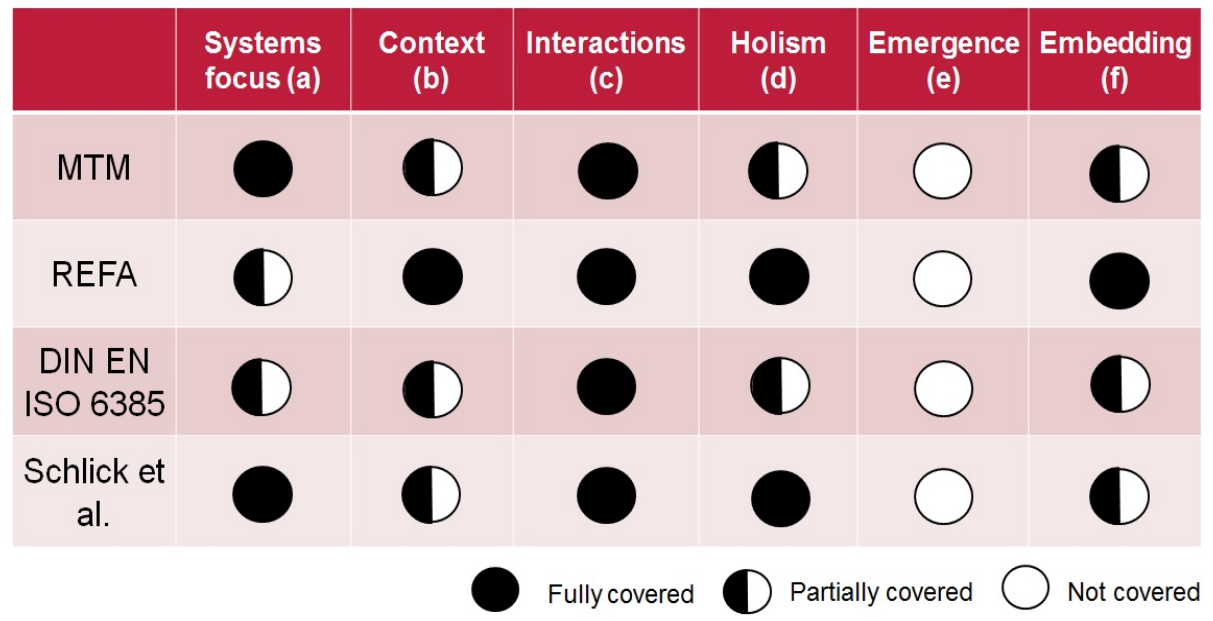

Fig. 1. Evaluation matrix for different work system models

Within a research assistant team of the group factory planning and ergonomics, the different degrees of coverage were identified and will be explained in the following section. For this evaluation, all features are weighed equally as the focus lies on the comparison of the different work systems. The coverage degrees are divided into three categories which are full, partial and no coverage of the particular feature. In detail, it explains the matching degree between the feature definition and the definitions made in the work system models. 


\section{$4 \quad$ Results}

The results of the evaluation are shown in figure 2. For each model, a coverage degree of the feature is assessed which will be explained in this section.

Obviously, there are two features which have the same coverage in all models. On the one hand, in every model the feature interaction is fully covered. This can be derived from the fact that all models have the focus on humans and the existing environment. In this environment, the person interacts with different things and turns the input, e.g. raw materials, into an output, e.g. products, by using tools. $[10,11,12,13]$ Besides the person-device-interaction, all models describe an interaction on an organizational level, e.g. between teams. On the other hand, all models do not cover the feature emergence. This is due to the fact that no possibility of other usage of the designed process is considered and no possibility of a continuous improvement process is included in a work system. One potential to cover the feature emergence can be a knowledge feedback as an input of the process.

The other features vary in the degree of coverage in the different models. System focus is only covered fully by the models of MTM and Schlick. The reason is that both models consider, in addition to the micro level, the macro level as well. MTM includes the macro-level in its definition of work systems whereas Schlick includes the macro-level in the extended model of a work system. [10, 13] REFA and DIN do not fully consider systems focus since those two models do partially include macrolevels of systems. REFA uses its work system by definition to describe the work. [11] It is not referred to the macro-level as it is in MTM or Schlick. More apparent is it in the definition in the DIN norm. There is no reference to the macro-level. [12]

Holism is fully covered by two models as well. Here, REFA and Schlick integrate this feature, by definition, the best. Those two models use different viewpoints in their work systems, for instance emotional or physical, to evaluate the system. Therefore, a holistic overview of the system can be derived. In comparison, MTM and DIN do consider the feature partly, but not in depth as the other two models.

The features context and embedding are the most heterogeneous features. For the feature embedding, only REFA covers it fully. This is due to the definition of REFA that the work system is integrated in the overall organization. The other models do not refer to it explicitly and therefore only cover it partially. Context is only fully covered by REFA as well. It is related to the feature embedding and the integration in the organization. With this, it is possible to evaluate the influences of the environment on a human. The other models do only partially cover the feature embedding and, consequently, it cannot give a complete overview as in the REFA model.

It is shown that the REFA work system model covers four out of six features and receives the best results in this evaluation. In comparison, the models of MTM and Schlick cover only three or respectively two features fully. The DIN norm only covers one feature fully. This result is due to the fact of the inherent character of a norm and its general application for any case. However, there is no model which covers all features. Especially the changing environment caused by megatrends and its impacts on the work system are not described. In addition, no integration of possible emergence and continuous improvement processes are given. As a consequence, work system 
models are changed from a static to a dynamic model by implementing a feedback cycle. This can be advantageous as early changes in a process can be done with little effort and cost. [20]

\section{Conclusion}

The requirements on work systems are changing due to the identified megatrends. These five megatrends have a big impact not only on the company itself but on the employee and the work system as well. Especially the demographic change will become important because people will get older and work longer in their lives. Hence, it is important to examine and evaluate work systems. There are just few models which consider a work system. Those depicted models do all have a different structure and vary in their definitions. Thus, a framework has to be defined in order to evaluate the existing models. Two possibilities were given and examined whereas the approach by Wilson showed to be the best choice for an evaluation framework. The features of the framework were evaluated for the models by an expert team. It was shown that no model can cover all the features to a full extent. As a result, none of those models do consider all aspects which will become important for the future. Thus, we are developing a work system model which is able to include all features of the framework and cover those to a full extent. The model will be introduced in further publications.

\section{References}

[1] Choudhury, M.A.: Global megatrends and the community. World Futures: Journal of General Evolution 53(3), 229-252 (1999)

[2] Hughes, D.: Demographic Changes and Megatrends. Foundation for Re-search Science and Technology New Zealand, FRST (1999)

[3] Tikkanen, T.: Innovative Capability and Productivity: What has Demographic Change to do with it? In: Jeschke, S., Isenhardt, I., Hees, F., Trantow, S. (eds.) Enabling Innovation, pp. 249-266. Springer, Heidelberg (2011)

[4] WDA Forum, Univerity of St. Gallen, Megatrend, Global Demographic Change: Tackling Business and Society Challenges in 2030 and beyond. St. Gallen (2011)

[5] Dombrowski, U., Ernst, S., Riechel, C.: Methodenframework der Fabrik-planung (MeFa). Wt Werkstattstechnik Online 104(4) (2014)

[6] Bruhn, M., Blockus, M.-O.: Komplexität bei Dienstleistungen. In: Töpfer, A., Hünerberg, R. (eds.) Gabler Research: Forum Marketing, Ganzheitliche Unternehmensführung in dyna-mischen Märkten: Festschrift für Univ.-Prof., 1st edn., pp. 27-47. Gabler, Wiesbaden (2009)

[7] Dombrowski, U., Evers, M., Riechel, C.: Demografiefeste Arbeitssystem-gestaltung: Am Beispiel eines adaptiven Arbeitsplatzes. ZwF Zeitschrift für wirtschaftlichen Fabrikbetrieb 108(9), 674-677 (2013)

[8] Tivig, T., Frosch, K., Kühntopf, S.: Mapping Regional Demographic Change and Regional Demographic Location Risk in Europe. Rostock Center for the Study of Demographic Change, Series on Sustainability and CSR 2 (2008) 
[9] Dombrowski, U., Hellmich, E.-M., Evers, M.: Arbeitswissenschaft in Deutschland: Bedeutung, Entwicklung und zukünftige Herausforderungen. Industrial Engineering (3), 3033 (2012)

[10] Bokranz, R., Landau, K.: Produktivitätsmanagement von Arbeitssystemen: MTMHandbuch. Schäffer-Poeschel, Stuttgart (2006)

[11] Hammer, W.: Wörterbuch der Arbeitswissenschaft: Begriffe und Definitionen, 1st edn. Hanser, München (1997)

[12] Grundsätze der Ergonomie für die Gestaltung von Arbeitssystemen, DIN EN ISO 6385 (2004)

[13] Schlick, C.: Arbeitswissenschaft, 3rd edn. Springer, Heidelberg (2010)

[14] Dul, J., Bruder, R., Buckle, P., Carayon, P., Falzon, P., Marras, W., Wilson, J.R., van der Doelen, B.: A strategy for human factors/ ergonomics: developing the discipline ad profession. Ergonomics, 377-395 (2012)

[15] The Discipline, I.E.A.: of Ergonomics, http: / / www . iea.cc/whats / index. html

[16] Karwowski, W.: The discipline of Human Factors and Ergonomics. In: Salvendy, G. (ed.) Hand-Book of Human Factors and Ergonomics, 4th edn., pp. 3-33. John Wiley \& Sons, Hoboken (2012)

[17] Neumann, W.P., Dul, J.: Human factors: spanning the gap between OM and HRM. International Journal of Operations \& Production Management 30(9), 923-950 (2010)

[18] Wilson, J.R.: Fundamentals of systems ergonomics/ human factors. Applied Ergonomics 45, 5-13 (2014)

[19] Grote, G.: Adding a strategic edge to human factors/ergonomics: Principles for the management of uncertainty as cornerstones for system design. Applied Ergonomics 45(1), 3339 (2014)

[20] Hauser, J.R., Clausing, D.: The house of quality. Harvard Business School, Pub. Division, Boston (1988) 